\title{
PLATONISMO ANTI-HERÉTICO?
}

ATHANASSIADI, Polymnia. La lutte pour l'orthodoxie dans le platonisme tardif: de Numénius à Damascius. Paris: Les Belles Lettres, 2006.

Maurício Pagotto Marsola*
mauriciomarsola@uol.com.br

Compreender a tradição platônica, considerando o arco que se estende de Numênio a Damáscio, pela designação de platonismo tardio faz com que o estudioso possa situar-se em duas perspectivas fundamentais. Que tal platonismo forma-se como continuidade temática e reflexiva com relação à tradição filosófica grega anterior a ele. E, em segundo lugar, que o fio condutor que a articula é sua fidelidade a Platão, sobretudo em sua releitura de outros filósofos, como Aristóteles ou os estóicos. O estudo de Polymnia Athanassiadi, La lutte pour l'orthodoxie dans le platonisme tardif, parte da idéia de que os escritos platônicos constituem um cânon cujo seguimento é o que caracteriza o procedimento exegético da escola. No grande ecúmeno no qual ocorre a constituição e afirmação das tradições das assim chamadas "religiões do livro", a tradição platônica tardia formar-se-ia na luta pela ortodoxia. Trata-se de uma leitura moderna pretender compreender os autores de modo fragmentado, separando-os da aíresis platônica. Portanto, pode-se considerar que a perspectiva presente nos estudos contemporâneos fragmentam e desvinculam tal platonismo de seu Sitz-im-Leben.

* Professor de História da Filosofia Antiga na Universidade Federal de São Paulo (Unifesp), São Paulo, Brasil.

KRITERION, Belo Horizonte, nº 116, Dez/2007, p. 499-504. 
1. Relacionada ao culto da figura de um Platão divinizado, o "divino Platão", sabe-se que o termo platônikós denota uma escolha espiritual, com tudo aquilo que a opção implica de crença metafísica, visão teórica do mundo, atitude moral e gênero de vida (cf. p. 23). É nesse sentido que aquelas designações de "médio" ou "neo" platonismo são calcadas em classificações artificiais e distinções que seriam incompreensíveis aos olhos dos próprios platônicos. E eles partilharam da luta cotidiana contra a "hidra da heterodoxia" (p. 23). Há uma idéia fundamental que baliza os termos de tal ortodoxia, qual seja, a noção de heresia, relacionada à polissemia do termo aíresis, que guardará dois sentidos fundamentais: a) Designa, inicialmente, a pertença a uma escola filosófica, remetendo-se ao sentido, comum no período helenístico, de uma doutrina filosófica, com seu modo de vida. Divorciada da escola, em seu sentido unicamente topográfico e institucional, a aíresis estóica, epicúrea ou cínica constitui um código de vida e pensamento válido em qualquer parte do ecúmeno (cf. p. 22). b) Mas aíresis passa progressivamente a designar o estar fora da doutrina, referindo-se àqueles que sustentam uma doutrina perniciosa.

Tal ambigüidade pode ser vista em um texto dos Atos dos apóstolos (24, 5), citado precisamente para indicar os elementos partilhados pelos grupos religiosos ou filosóficos do período. Na referida narrativa, Paulo é acusado de pertencer a uma seita (aíresis tôn Nazôraiôn), em sentido pejorativo. Paulo diz pertencer a uma aíresis, empregando o termo em seu sentido helenístico, isto é, de uma escola de pensamento e de vida. Mas em $2 \operatorname{Pd} 2$, 1, aíresis aparece novamente em sentido negativo: "Haverá falsos doutores que introduzirão sorrateiramente doutrinas perniciosas (aíresis apôleías)". Logo, a aíresis, no sentido de escolha de vida, torna-se a heresia, tomada como um outro modo de ver, de pensar e sentir perigoso, inadequado com relação à correta exegese da revelação; portanto, condenável e perecível (cf. p. 21).

Ora, Athanassiadi questiona se os platônicos continuam a empregar o termo em seu sentido helenístico, notando que:

Plenamente integrados em sua sociedade, os gurus do platonismo entregam-se a um combate cotidiano pela formação de uma regra de fé fundada sobre a leitura e a interpretação orientada de um conjunto de textos que estão à disposição da comunidade dos que escrevem e se dizem pertencentes à família platônica (p. 22, grifo nosso).

Além disso, tomada como um sistema fechado, formado por um número definido de textos, que apóiam sua autoridade na revelação divina, a noção de cânon, da qual deriva uma leitura canônica da tradição filosófica, elimina 
do percurso intelectual todas as leituras concorrentes (cf. p. 28). Tal o critério para que os platônicos pudessem distinguir erro e verdade, configurando-se assim um "discurso platônico" ortodoxo (cf. p. 114). Partícipe de um Zeitgeist (noção recuperada nesse contexto, cf. p. 26), o platonismo partilharia com seus contemporâneos cristãos a mesma recusa da heterodoxia com relação à doutrina estabelecida (cf. p. 112-116). Aliás, Athanassiadi nota que há uma grande quantidade de estudos a esse respeito, relativos às tradições judaica e cristã, mas a quase completa ausência da consideração desse aspecto no âmbito do platonismo do período.

A diversidade existente entre tais autores poderia negar o mito da continuidade, mas foram os próprios platônicos que inventaram e perpetuaram uma "mitologia da escola" (p. 24). Plotino, segundo Athanassiadi, interpreta a herança platônica como uma "teologia". Jâmblico, por sua vez, lança as bases para a criação de uma comunidade religiosa. Por outro lado, é a figura de Numênio que inicia uma "cadeia mística", enraizando Platão na tradição pitagórica e, de outro lado, purificando a árvore platônica de todo parasita cético. A estrutura da obra constrói-se, portanto, realizando uma análise de cada caso de consolidação desta "cadeia de ouro" (chaîne d'or) do platonismo. Um dos eixos para a compreensão do caráter revelado do platonismo é a formação e consolidação dos Oráculos caldáicos, aos quais é dedicado todo o capítulo 1, como uma espécie de escritura sagrada. Após considerar o problema da revelação e constituição do cânon, a análise volta-se para os referidos casos de Numênio, Plotino, Jâmblico e Damáscio. Os platônicos seriam, segundo este último filósofo, uma "raça de homens divinos" (génos theíôn anthrôpôn), distinguindo-se dos outros e vivendo de modo separado da sociedade (cf. p. 25).

Tal idéia de que os platônicos formam uma "raça sagrada" já estaria presente em Plotino. Athanassiadi apóia-se em V 9 [5], 1, 16, notando, contudo, a ausência do caráter "ascético" que estará presente em Damáscio. Todavia, em ambos os casos, o dado essencial é a superioridade da comunidade platônica. Aliás, é nesse texto do tratado 5, conforme a ordem cronológica das Enéadas, que se lê uma recusa aos epicuristas, por não conseguirem desvencilhar-se do sensível, e aos estóicos, por estarem presos ao mero âmbito da práxis. Isso confirma as observações feitas segundo as quais há, já em Plotino, uma imagem da história da Filosofia, estritamente afirmativa, de um ponto de partida canônico com relação a Platão.

2. É nessa perspectiva que Athanassiadi toma, no caso de Plotino, as refutações à aíresis dos gnósticos, que comporiam uma verdadeira paideía antignóstica (composta pelos tratados 30,31, 32 e 33), para empregar os termos 
de V. Cilento, tese partilhada por outros estudiosos (como Harder e Hadot). Athanassiadi nota que há uma mudança de tom no tratado 33 (segundo a ordem cronológica dos escritos) com relação aos tratados anteriores $(30,31$ e 32), nos quais os argumentos antignósticos eram comparáveis aos argumentos contra Aristóteles ou os epicuristas, isto é, mantendo uma crítica em tom sereno. Contrasta com tal postura a ironia e a virulência dos argumentos presentes no tratado 33, o que permite que Athanassiadi o interprete como um tratado único, opondo-se à leitura corrente, que o relaciona aos três tratados anteriores (p. 124). É correto dizer que é a audácia (tolma) gnóstica o elemento a partir do qual Plotino entende a temeridade filosófica, isto é, o afastar-se da tradição daquela verdade há muito enunciada pelos antigos e da qual o filósofo não é mais do que exegeta. É tal audácia o pólo do qual irradia toda uma série de impropriedades filosóficas enunciadas pelos gnósticos, "bestas negras" (bêtes noires) para Plotino, conforme o título do capítulo 4 (p. 121-145). Note-se, ainda, que Plotino mobilizaria contra eles o arsenal heresiológico da época (p. 135).

Além de se apoiar quase que unicamente no tratado contra os gnósticos e no texto de V 1 [10], 8, Athanassiadi radicaliza seu prisma analítico, dizendo que Plotino pode agrupar tais impropriedades que afastam seus interlocutores da tradição sob o título de heresia, isto é, aqueles que já estão fora da autêntica aíresis. Apesar da pertinência do fato de não podermos "modernizar" a interpretação, fragmentando a tradição na qual Plotino está inserido, com dificuldade, podemos deixar de nuançar tal perspectiva quando consideramos, mais longamente, nos primeiros capítulos do texto de III 7 [45], o famoso tratado Sobre a eternidade e o tempo. Com relação a tal texto, T. A. Szlezák, em seu Plato und Aristoteles in der Nuslehre Plotin, já notava que não podemos dizer que há uma pretensão clara de afastamento do platonismo por parte de Plotino. Em outras palavras, dificilmente podemos dizer que há uma perspectiva crítica plotiniana com relação a Platão. Talvez não possamos, efetivamente, sustentar uma tese contrária a essa afirmação, mas repensando a constituição do campo exegético plotiniano, podemos considerar a noção de que a verdade pode ser investigada pelo contato noético que se articula pelo exercício rememorativo, tal como os antigos o fizeram, e que aparece de modo claro no referido texto plotiniano. Nele, Plotino elabora uma espécie de exame doxográfico, no qual são examinadas as opiniões sobre o tempo, concluindo com uma pretensão de posicionamento autônomo com relação à questão. $\mathrm{Ou}$ seja, sua postura essencialmente zetética guarda uma nuance com relação à ortodoxia platônica.

O estudo de Athanassiadi ressalta que Plotino se comporta segundo uma mentalidade canônica, uma vez que a rejeição de alguns autores visa à tarefa 
de estabelecer e reafirmar a única interpretação válida da metafísica de Platão (cf. p. 28). Aliás, a referência textual é, aqui, a passagem da Vita Plotini, 14, 17, na qual Porfírio diz que seu mestre lia os textos platônicos, interpretandoos segundo o espírito de Amônio. Athanassiadi lê esse relato porfiriano como indicando uma referência a tal interpretação ortodoxa, "canônica". Ora, se situarmos, contudo, o texto em seu contexto estrutural, essa perspectiva não aparece com clareza, pois Porfírio ressalta, de início, a diferença do método de leitura plotiniana dos textos platônicos com relação à filologia alexandrina (Vita Plotini, 14, 18-20). Plotino lê os textos de Platão como filósofo e não como filólogo, afirmação que nos remete ao sentido de "filósofo" nos diálogos platônicos (veja, por exemplo, o comentário de J. Pépin a essa passagem em: La vie de Plotin. Paris: Vrin, 1992. v. 2. p. 477-501).

3. Se assumirmos a perspectiva de leitura da exegese plotiniana de Platão, considerada de um ponto de partida canônico ou de um platonismo ortodoxo, como pretende esse notável estudo, as dificuldades permanecem. Aliás, além de podermos ponderar que a passagem da noção de cânon em seu sentido cristão ao sentido pagão (platônico) é feita com um salto, configurando um hiato com relação à praxe exegética plotiniana (cf., por exemplo, p. 114), teríamos de assumir uma tese já defendida, embora sob outra perspectiva, por vários intérpretes de Plotino. A idéia é que Plotino encontra, em Platão, uma doutrina, não um conjunto de teses filosóficas a partir das quais se fará o itinerário investigativo do lógos. Ora, de um lado, sabemos que a formação de um “corpus canônico" platônico não se cristaliza senão a partir de Jâmblico (cf. a própria observação de Athanassiadi, p. 28). De outro, é por essa razão que o conteúdo nuançado dos textos de Plotino ou Proclo se distancia enormemente das características presentes nos últimos platônicos que fecham a síntese religiosa do mundo tardo-antigo, ou seja, a de um universo do sobrenatural, do mágico e do teúrgico (cf. p. 29).

Uma palavra, ainda, sobre a divinização de Platão ressaltada pelo estudo. O sentido da designação de "o divino Platão" e "homens divinos e bem-aventurados", referindo-se à tradição anterior, é muito diverso, se compararmos sua significação em Plotino com relação a Damáscio. Se, no último, há uma perspectiva religiosa, que se consolida em Jâmblico, em Plotino, essas referências aparecem no interior de contextos exegéticos, nos quais o filósofo examina as opiniões e teses a respeito de uma determinada questão, tal como, por exemplo, a dos primeiros princípios da realidade. Tal é o caso do modo como aparecem no tratado V 1 [10], 8, que versa sobre as hipóstases ou princípios do real. Ou, ainda, em VI 9 [9], 11, 45-51, a makaria e a eudaimonia referem-se aos que buscam a similitude com o divino 
no processo de ascensão para o Uno; esses são os verdadeiramente homens divinos e felizes. Nesse sentido, a pertença filosófica à família platônica seria menos um a priori do que uma conseqüência de tal itinerário.

Instigante e complexo, por obrigar o leitor, no mínimo, a repensar seus paradigmas interpretativos e por transportá-lo para o coração do contexto filosófico-religioso da Antigüidade tardia, o estudo leva à discussão crucial da impossibilidade de se compreender, de modo adequado, o platonismo tardio, sem que se considere seu posicionamento frente ao passado. É a partir de tal posicionamento que se inicia a démarche filosófica de cada um dos platônicos, em sua situação vital e em seu processo de formação. Aberta é a questão do teor e do estatuto do fio condutor que articula a postura filosófica específica de cada um deles, o que circunscreve a tensão entre tempo lógico e tempo histórico, continuidade e ruptura. 